\title{
Preface: Outcome Measurement in Physical Therapy I
}

In addition to other functions, outcome measures enable rehabilitation practitioners to determine the level of impairment in a given patient, facilitate goal setting, and assess response to treatment. By virtue of these three overarching objectives, outcome measures improve the delivery of targeted interventions to address key impairments in a patient, thereby enhancing the quality of care. Outcome measures used in rehabilitation capture patient impairments through broader constructs of body structure/function, activity limitations, and participation restrictions, as outlined in the International Classification of Functioning, Disability, and Health. Rehabilitation practitioners most commonly target their interventions to mitigate impairment across these constructs. ${ }^{1}$ Therefore, using outcome measures that assess a variety of impairments and assist in planning focused treatment validates the delivery of appropriate rehabilitation interventions.Several considerations for using outcome measures in rehabilitation practice must be considered. First, an outcome measure should provide assessment of the most pertinent impairment resulting from a particular condition. Secondly, the measure should have a robust body of evidence that supports its measurement properties, including reliability, validity, and sensitivity to change. An outcome measure that has stellar measurement properties for use in a particular condition creates a very useful tool for targeting specific therapeutic interventions in a patient. Third, the outcome measure should be easyily administered and scored. Measures that need elaborate instrumentation and take a long time to complete and score can result in poor integration in clinical practice.One of the major barriers for efficiently integrating research evidence into a health-care setting is hard-to-read, lengthy articles that are often written using scientific terminology. Consequently, providing a summary of measurement properties of an outcome measure and contextualizing these properties for potential purposes in clinical practice can greatly facilitate their understanding and clinical role. Health-care providers can learn key details of a measure via relatively short articles. Therefore, we envisioned a short summary of an outcome measure that describes key aspects including the structure, administration, measurement properties, and key recommendations for use in clinical practice. This issue integrates short summaries involving 12 commonly used outcome measures in the rehabilitation setting for assessing impairments in a wide spectrum of the patient population. It is our hope that physical therapists and other rehabilitation practitioners find these summaries to be useful, easy to read as well, and helpful in informing their use in daily practice. The 12 measures are listed below.

\section{Bruininks-Oseretsky Test of Motor Proficiency II $^{2}$}

2. HiMAT: High-Level Mobility Assessment Tool ${ }^{3}$ 
3. Hospital Anxiety and Depression Scale ${ }^{4}$

4. Functional Reach Test ${ }^{5}$

5. MCTSIB: Modified Clinical Test of Sensory Integration for Balance ${ }^{6}$

6. A Short Summary of Hop Tests ${ }^{7}$

7. Physical Performance Test (PPT) ${ }^{8}$

8. Patient Health Questionnaire $9^{9}$

9. International Physical Activity Questionnaire ${ }^{10}$

10. Agitated Behavior Scale ${ }^{11}$

11. Trunk Impairment Scale ${ }^{12}$

\section{The Star Excursion Balance Test ${ }^{13}$}

In the second part of Outcome Measurement in Physical Therapy, scheduled to be produced later this year, we anticipate publishing several other summary articles of outcome measures.

\section{Guest Editor:}

Saurabh Mehta, Ph.D.

School of Physical Therapy

Marshall UniversityHuntington, West Virginia, USA

\section{REFERENCES}

1. Hart T, Tsaousides T, Zanca JM, Whyte J, Packel A, Ferraro M, Dijkers MP. Toward a theory-driven classification of rehabilitation treatments. Arch Phys Med Rehab. 2014;95(1 Suppl):S33-44.e32.

2. Mason A, Hively A, Itani B, loop W. Bruininks-Oseretsky Test of Motor Proficiency II. Crit Rev Phys Rehab Med. 2019;29(2):93-95. DOI: 10.1615/CritRevPhysRehabilMed.2018026244

3. Pfost G, Cook B, Doh C, Uthupan J. HiMAT: High-Level Mobility Assessment Tool. Crit Rev Phys Rehab Med. 2018;29(2):97-99.

4. Mehta SP, Crochet Z, O’Dell N, Stevenson A. Hospital Anxiety and Depression Scale. Crit Rev Phys Rehab Med. 2018;29(2):101-103.

5. Mason A, Lum J, Milligan A, Robinson J. Functional Reach Test. Crit Rev Phys Rehab Med. 2018;29(2):105-107.

6. Pfost G, Chen A, Farley F, Ran Y, Sanchez V. MCTSIB: Modified Clinical Test of Sensory Integration for Balance. Crit Rev Phys Rehab Med. 2018;29(2):109-112. 
7. Mehta SP, Chang K, Malave C, Mcguire A. A short summary of Hop Tests. Crit Rev Phys Rehab Med. 2018;29(2):113-115.

8. Mason A, Foderaro F, Kawash M, Keene D. Physical Performance Test (PPT). Crit Rev Phys Rehab Med. 2018;29(2):117-119.

9. Pfost G, Hoffman K, Jackson S, Park JH. Patient Health Questionnaire-9. Crit Rev Phys Rehab Med.2018;29(2):121-123.

10. Mehta SP, Jarvis A, Standifer D, Warnimont C. International Physical Activity Questionnaire. Crit Rev Phys Rehab Med. 2018;29(2):125-127.

11. Mason A, Bitnet D, Green R, Harper M. Agitated Behavior Scale. Crit Rev Phys Rehab Med. 2018;29(2):129-131.

12. Pfost G, Cyrus H, Franzen B, Helton T. Trunk Impairment Scale. Crit Rev Phys Rehab Med. 2018;29(2):133-135.

13. Mehta SP, Bremer H, Pfleghaar J, Ramey A. The Star Excursion Balance Test. Crit Rev Phys Rehab Med. 2018;29(2):137-139. 
